University of North Florida

UNIVERSITY of

NORTH FLORIDA.

UNF Digital Commons

\title{
The Effects of Small Metal Additions (Co,Cu,Ga,Mn,Al,Bi,Sn) on the Magnetocaloric Properties of the Gd5Ge2Si2 Alloy
}

\author{
R D. Shull \\ V Provenzano \\ A J. Shapiro \\ $\mathrm{AFu}$ \\ Michael W. Lufaso \\ University of North Florida, michael.lufaso@unf.edu
}

See next page for additional authors

Follow this and additional works at: https://digitalcommons.unf.edu/achm_facpub

Part of the Chemistry Commons

\section{Recommended Citation}

Shull, R D.; Provenzano, V; Shapiro, A J.; Fu, A; Lufaso, Michael W.; Karapetrova, J; Kletetschka, G; and Mikula, $\mathrm{V}$, "The Effects of Small Metal Additions (Co,Cu,Ga,Mn,Al,Bi,Sn) on the Magnetocaloric Properties of the Gd5Ge2Si2 Alloy" (2006). Chemistry Faculty Publications. 9.

https://digitalcommons.unf.edu/achm_facpub/9

This Article is brought to you for free and open access by the Department of Chemistry at UNF Digital Commons. It has been accepted for inclusion in Chemistry Faculty Publications by an authorized administrator of UNF Digital Commons. For more information, please contact Digital Projects.

(C) 2006 All Rights Reserved

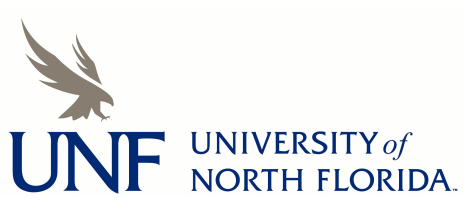




\section{Authors}

R D. Shull, V Provenzano, A J. Shapiro, A Fu, Michael W. Lufaso, J Karapetrova, G Kletetschka, and V Mikula

This article is available at UNF Digital Commons: https://digitalcommons.unf.edu/achm_facpub/9 


\title{
The effects of small metal additions ( $\mathrm{Co}, \mathrm{Cu}, \mathrm{Ga}, \mathrm{Mn}, \mathrm{Al}, \mathrm{Bi}, \mathrm{Sn})$ on the magnetocaloric properties of the $\mathrm{Gd}_{5} \mathrm{Ge}_{2} \mathrm{Si}_{2}$ alloy
}

\author{
R. D. Shull, ${ }^{\text {a) }}$ V. Provenzano, A. J. Shapiro, and A. Fu \\ National Institute of Standards and Technology, 100 Bureau Drive, Gaithersburg, Maryland 20899-8552 \\ M. W. Lufaso \\ Department of Chemistry and Biochemistry, University of South Carolina, 631 Sunter Street, Columbia, \\ Southern Carolina 60439

\section{J. Karapetrova} \\ Advanced Photon Source, Argonne National Laboratory, 9700 S. Cass Avenue, Argonne, Illinois 60439
}

\section{G. Kletetschka}

Department of Physics, Catholic University of America, Washington DC and Goddard Space Flight Center, NASA Code 691, Greenbelt, Maryland

\section{Mikula}

Department of Physics, Catholic University of America, Washington DC and Geological Institute, Academy of Science, Prague, Czech Republic

(Presented on 2 November 2005; published online 26 April 2006)

\begin{abstract}
The structural and magnetic properties of arc-melted and homogenized $\left(1300{ }^{\circ} \mathrm{C}, 1 \mathrm{~h}\right)$ alloys of $\mathrm{Gd}_{5} \mathrm{Ge}_{1.9} \mathrm{Si}_{2} X_{0.1}(X=\mathrm{Cu}, \mathrm{Co}, \mathrm{Ga}, \mathrm{Mn}, \mathrm{Al}, \mathrm{Bi}$, or $\mathrm{Sn})$ were investigated by powder X-ray diffraction, scanning electron microscopy, energy dispersive spectroscopy, and magnetometry. The addition of $\mathrm{Cu}, \mathrm{Ga}, \mathrm{Mn}$, and $\mathrm{Al}$ completely eliminated the large hysteresis losses present in the undoped $\mathrm{Gd}_{5} \mathrm{Ge}_{2} \mathrm{Si}_{2}$ alloy between 270 and $330 \mathrm{~K}$, broadened the magnetic entropy change $\Delta S m$ peak, and shifted its peak value from 275 to $305 \mathrm{~K}$ similar to that observed earlier for $\mathrm{Gd}_{5} \mathrm{Ge}_{1.9} \mathrm{Si}_{2} \mathrm{Fe}_{0.1}$. The addition of $\mathrm{Bi}$ or $\mathrm{Sn}$ had a negligible effect on either the alloy hysteresis losses or the characteristics of the $\Delta S_{m}$ vs $T$ peak. The microstructure of the alloy doped with $\mathrm{Cu}, \mathrm{Co}, \mathrm{Ga}, \mathrm{Mn}$, or $\mathrm{Al}$ consisted of a majority phase (depleted of silicon) and a minor intergranular phase (rich in silicon and of the corresponding metal additive). For $\mathrm{Bi}$ or $\mathrm{Sn}$ doping, the microstructure consisted of only the $\mathrm{Gd}_{5} \mathrm{Ge}_{2} \mathrm{Si}_{2}$ phase. Low temperature X-ray diffraction data on an Fe-doped sample showed the same spectra at 245 and $300 \mathrm{~K}$, consistent with the majority phase possessing an orthorhombic structure. Refrigeration capacity calculations show that $\mathrm{Gd}_{5} \mathrm{Ge}_{1.9} \mathrm{Si}_{2} X_{0.1}(X=\mathrm{Fe}, \mathrm{Cu}, \mathrm{Co}, \mathrm{Ga}, \mathrm{Mn}, \mathrm{or} \mathrm{Al})$ alloys are superior magnetic refrigerants compared to the undoped $\mathrm{Gd}_{5} \mathrm{Ge}_{2} \mathrm{Si}_{2}$ alloy. (C) 2006 American Institute of Physics. [DOI: 10.1063/1.2173632]
\end{abstract}

\section{INTRODUCTION}

Since the late 1990s, a great deal of attention has been focused on the $\mathrm{Gd}_{5} \mathrm{Ge}_{2} \mathrm{Si}_{2}$ compound as a potential near room temperature magnetic refrigerant because of its large ("giant") magnetocaloric effect $\left(\Delta S_{m}\right)$ between 270 and $300 \mathrm{~K}^{1-3}$ Unfortunately this material also possesses large hysteretic losses in this same temperature range, thereby reducing its efficiency. ${ }^{4}$ Recently, it was shown that doping the $\mathrm{Gd}_{5} \mathrm{Ge}_{2} \mathrm{Si}_{2}$ compound with iron decreased its large hysteresis losses by more than $90 \%$. In addition, the $\Delta S_{m}$ peak was broader and its peak value shifted from 275 to $305 \mathrm{~K}$, compared to the undoped compound. ${ }^{6}$ Moreover, even though, the peak $\Delta S_{m}$ value of the Fe-doped compound was smaller than that of the undoped compound, its corresponding refrigeration capacity $(\mathrm{RC})$ value was $20 \%-50 \%$ larger (depending on the criterion used to compute the RC values) if the hysteresis losses were taken into account. These results clearly showed that the Fe-doped compound is a much more useful magnetic refrigerant than the undoped $\mathrm{Gd}_{5} \mathrm{Ge}_{2} \mathrm{Si}_{2}$ compound.

${ }^{a)}$ Electronic mail: robert.shull@nist.gov
Further, it was concluded that the Fe-doping was effective in eliminating the hysteresis of the $\mathrm{Gd}_{5} \mathrm{Ge}_{2} \mathrm{Si}_{2}$ compound because it prevented the $\mathrm{Gd}_{5} \mathrm{Ge}_{2} \mathrm{Si}_{2}$ transformation to the monoclinic $\left(P 2_{1} / a\right)$ phase at $T \geqslant 270 \mathrm{~K}$. To experimentally test these early conclusions and to determine whether $\mathrm{Fe}$ doping was unique in causing these changes, this work on the $\mathrm{Gd}_{5} \mathrm{Ge}_{2} \mathrm{Si}_{2}$ compound doped with several different metal additives was initiated.

\section{EXPERIMENTAL PROCEDURE}

Samples in the present study were prepared by arc melting. The doped ones were prepared at NIST, whereas the undoped alloy was prepared at the Ames Laboratory, Ames, IA. The purity of the starting constituents was $99.9 \%$ mass fraction or better; and the target compositions were either $\mathrm{Gd}_{5} \mathrm{Ge}_{2} \mathrm{Si}_{2}$ or $\mathrm{Gd}_{5} \mathrm{Ge}_{1.9} \mathrm{Si}_{2} X_{0.1}(X=\mathrm{Cu}, \mathrm{Co}, \mathrm{Ga}, \mathrm{Mn}, \mathrm{Al}, \mathrm{Bi}$, or $\mathrm{Sn})$. All samples were homogenized at $1300{ }^{\circ} \mathrm{C}$ for $1 \mathrm{~h}$ in vacuum, ${ }^{2}$ and then characterized by $\mathrm{Cu} K \propto$ X-ray diffraction (XRD), scanning electron microscopy (SEM), and energy dispersive spectroscopy (EDS). The magnetocaloric effect on each alloy was determined by measuring the magnetization 


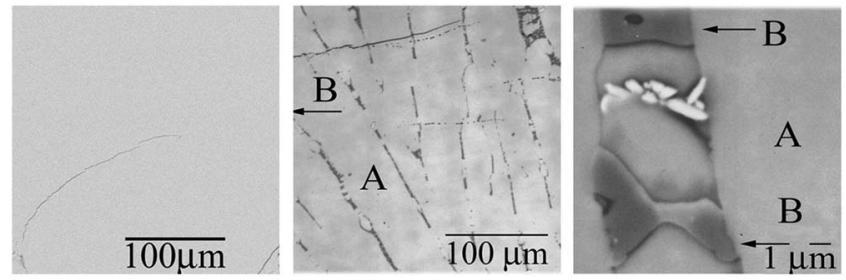

FIG. 1. Backscattered scanning electron micrographs showing typical microstructures of $\mathrm{Gd}_{5} \mathrm{Ge}_{2} \mathrm{Si}_{2}$ (a) and $\mathrm{Gd}_{5} \mathrm{Ge}_{1.9} \mathrm{Si}_{2} \mathrm{Cu}_{0.1}$ [(b) and (c)] alloy samples heat treated in vacuum at $1300{ }^{\circ} \mathrm{C}$ for $1 \mathrm{~h}$.

$(M)$ as a function of temperature and applied magnetic field $(H)$ using a superconducting quantum interference device (SQUID) magnetometer (calibrated by NIST SRM No. 772). The magnetic entropy change $\left(-\Delta S_{m}\right)$ was calculated in the usual way by numerically integrating the Maxwell relation: $(\partial S / \partial H)_{T}=(\partial M / \partial T)_{H}$. Low temperature x-ray measurements were made on an Fe-doped alloy sample, $\mathrm{Gd}_{5} \mathrm{Ge}_{1.9} \mathrm{Si}_{2} \mathrm{Fe}_{0.2}$, at the UNICAT 33-BM beam line 6 at the Advanced Photon Source (APS), Argonne National Laboratory. For these measurements, the polycrystalline sample was mounted on a closed-cycle He Displex cryostat on a flat plate, in the $\theta$ $-2 \theta$ reflection geometry. X-rays of wavelength $0.68873 \Delta$ were selected by a double crystal $\mathrm{Si}(111)$ monochromator calibrated using a NIST 640c silicon powder standard reference material. Room temperature $\mathrm{x}$-ray data for all the other alloys were measured in a conventional Phillips $\mathrm{x}$-ray diffractometer using $\mathrm{Cu} K \alpha$ radiation. $^{6}$

\section{RESULTS AND DISCUSSION}

Figure 1 compares the microstructure of the undoped $\mathrm{Gd}_{5} \mathrm{Ge}_{2} \mathrm{Si}_{2}$ compound to that of the compound doped with copper. As it may be observed from the backscattered SEM micrographs and consistent with the previous study on the Fe-doped compound, ${ }^{5}$ the microstructure of the compound without the metal additive is single phase [Fig. 1(a)], whereas that of the $\mathrm{Cu}$-doped alloy consists of a lighter majority matrix phase and an embedded darker minor phase [Fig. 1(b)]; Fig. 1(c) shows the minor phase to actually consist of three minor phases. EDS analysis showed that the majority matrix phase had a lower concentration of silicon compared to the undoped $\mathrm{Gd}_{5} \mathrm{Ge}_{2} \mathrm{Si}_{2}$ compound, while the metal additive was located primarily in the intergranular phases combined with $\mathrm{Si}$. These results imply that a certain amount of silicon in the $\mathrm{Cu}$-doped alloy segregated to the grain boundaries to form the $\mathrm{Cu}$ - and $\mathrm{Si}$-rich minority phases, thereby depleting the $\mathrm{Si}$ content of the majority phase. Figure 2 shows the x-ray diffraction patterns for the Fe-doped alloy, $\mathrm{Gd}_{5} \mathrm{Ge}_{29} \mathrm{Si}_{1.8} \mathrm{Fe}_{0.2}$, at $245 \mathrm{~K}$ and room temperature, compared to standard patterns for the orthorhombic (Pnma) and monoclinic $\left(P 2_{1} / a\right)$ structures of the undoped $\mathrm{Gd}_{5} \mathrm{Ge}_{2} \mathrm{Si}_{2}$. The spectrum for the Fe-doped alloy is essentially the same between $245 \mathrm{~K}$ and room temperature, and that pattern contains all the major reflections of the orthorhombic phase. Consequently, the earlier conclusion that one of the main effects of the $\mathrm{Fe}$ addition is to eliminate the monoclinic phase formation in $\mathrm{Gd}_{5} \mathrm{Ge}_{2} \mathrm{Si}_{2}$ is now confirmed by this direct structural probe. X-ray diffraction patterns

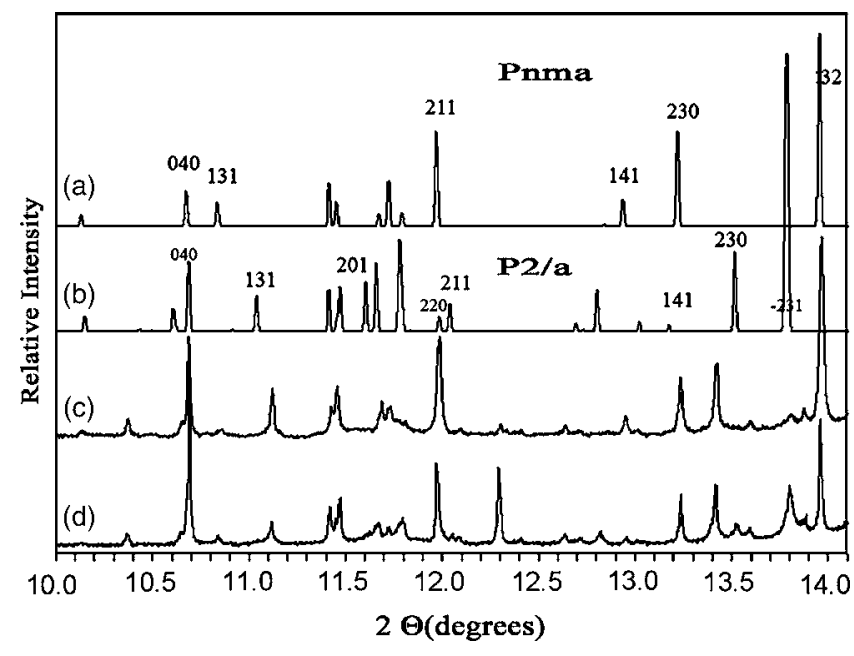

FIG. 2. $\mathrm{Cu} K \alpha$ x-ray diffraction patterns for (a) simulated Pnma (orthorhombic) $\mathrm{Gd}_{5} \mathrm{Ge}_{2} \mathrm{Si}_{2}$, (b) simulated $P 2_{1} / a$ (monoclinic) $\mathrm{Gd}_{5} \mathrm{Ge}_{2} \mathrm{Si}_{2}$, (c) $\mathrm{Gd}_{5} \mathrm{Ge}_{2} \mathrm{Si}_{1.8} \mathrm{Fe}_{0.2}$ at $245 \mathrm{~K}$, and (d) $\mathrm{Gd}_{5} \mathrm{Ge}_{2} \mathrm{Si}_{1.8} \mathrm{Fe}_{0.2}$ at ambient temperature. Selected Bragg reflections are labeled.

measured at room temperature for the $\mathrm{Gd}_{5} \mathrm{Ge}_{1.9} \mathrm{Si}_{2} X_{0.1}(X$ $=\mathrm{Cu}, \mathrm{Co}, \mathrm{Ga}, \mathrm{Mn}$, or $\mathrm{Al}$ ) alloys are similar to the previous results on the Fe-doped alloy. ${ }^{5}$ The main peaks of the $\mathrm{Gd}_{5} \mathrm{Ge}_{1.9} \mathrm{Si}_{2} X_{0.1}$ alloy, though slightly shifted, matched those of the $\mathrm{Gd}_{5} \mathrm{Ge}_{2} \mathrm{Si}_{2}$ orthorhombic phase; the few unmatched minor peaks are associated with the $\mathrm{Si}$ - and $\mathrm{Cu}$-rich minor phases seen in the SEM microstructure. By contrast the $\mathrm{x}$-ray patterns for the $\mathrm{Bi}$ - and $\mathrm{Sn}$-doped materials were very similar to that of the undoped material, i.e., of the monoclinic phase of the $\mathrm{Gd}_{5} \mathrm{Ge}_{2} \mathrm{Si}_{2}$ compound [Fig. 2(b)].

The $\mathrm{M}$ vs $T$ data measured at $796 \mathrm{kA} / \mathrm{m}(10 \mathrm{kOe})$ applied field at increasing temperatures for the undoped $\mathrm{Gd}_{5} \mathrm{Ge}_{2} \mathrm{Si}_{2}$ compound show a very sharp discontinuity at about $270 \mathrm{~K}$. This transition is associated with the crystallographic transformation from the low $T$ orthorhombic phase (ferromagnetic, with Curie point, $T_{C}$, above $270 \mathrm{~K}$ ) to the high $T$ paramagnetic monoclinic phase. ${ }^{7}$ On the other hand, the absence of a sharp transition in similarly measured data for the $\mathrm{Cu}$-doped compound shows that no crystallographic change occurred in this alloy. Instead, the gradual transition on heating for this latter alloy is the magnetic behavior usually associated with a single-phase ferromagnet at its Curie point, which in this case is near $300 \mathrm{~K}$. This Curie point value is consistent with the expected $T_{C}$ for the orthorhombic phase of the undoped $\mathrm{Gd}_{5} \mathrm{Ge}_{2} \mathrm{Si}_{2}$ compound if it had not transformed to the monoclinic structure at $T>270 \mathrm{~K} . M$ vs $T$ data for the Fe-doped alloy of Ref. 5 were also similar to that reported here for the $\mathrm{Cu}$-doped material. The isothermal $M$ vs $H$ data plots of the undoped compound show a fieldinduced magnetic transition between 270 and $300 \mathrm{~K}$; the field strength required for inducing the transition (under increasing field conditions) increased with increasing $T$. Previous studies have shown that this field-induced transition is associated with a monoclinic (paramagnetic) to orthorhombic (ferromagnetic) crystallographic phase change. ${ }^{7}$ By contrast, in the $260 \mathrm{~K}$ to $350 \mathrm{~K}$ temperature range, the corresponding plots for the $\mathrm{Cu}$-doped compound do not show such a field-induced transition, but instead only show a 


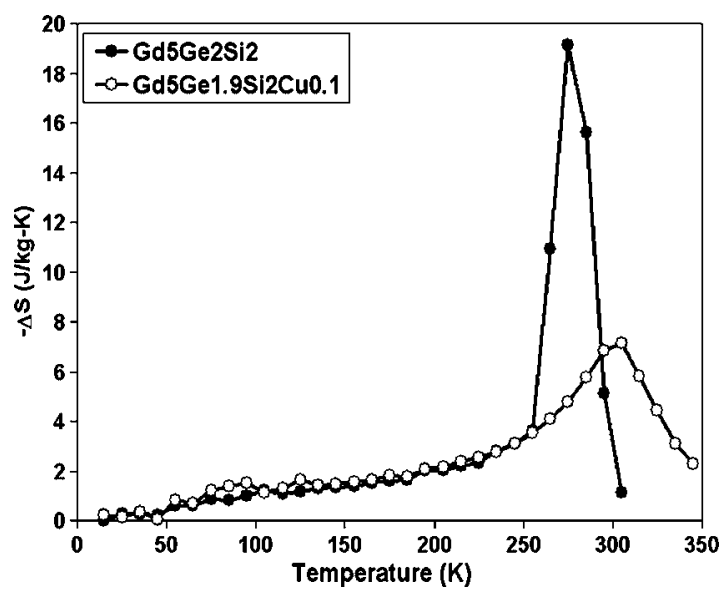

FIG. 3. Computed $-\Delta S_{m}$ values for the $\mathrm{Gd}_{5} \mathrm{Ge}_{2} \mathrm{Si}_{2}$ compound (filled symbols) and the $\mathrm{Gd}_{5} \mathrm{Ge}_{1.9} \mathrm{Si}_{2} \mathrm{Cu}_{0.1}$ alloy (open symbols), both vacuum were heat treated at $1300{ }^{\circ} \mathrm{C}$ for $1 \mathrm{~h}$, plotted as a function of temperature, and integrated over applied field, $\Delta H=3980 \mathrm{kA} / \mathrm{m}(50 \mathrm{kOe})$.

gradual ferromagnetic-to-superparamagnetic transition. The $M$ vs $H$ loops for the undoped compound show large hysteresis losses between 270 and $300 \mathrm{~K}$ which are not present for the $\mathrm{Cu}$-doped alloy. Consequently, the $\mathrm{Cu}$-doped alloy acts the same as previously observed in an Fe-doped alloy ${ }^{5}$ in that the elimination of the field-induced crystallographic transformation also eliminated the magnetic hysteresis. Similarly, the Al-, Ga-, and Mn-containing alloys also showed little hysteresis in this temperature range and the absence of a fieldinduced transition. The Co-doped alloy showed some hysteresis and a small amount of field-induced transformation.

The $-\Delta S_{m}$ vs $T$ plots presented in Fig. 3 compares the magnetocaloric responses of the undoped and $\mathrm{Cu}$-doped $\mathrm{Gd}_{5} \mathrm{Ge}_{2} \mathrm{Si}_{2}$ alloys. The undoped compound shows a large (20 J/kg K maximal value) but narrow $-\Delta S_{m}$ peak centered near $270 \mathrm{~K}$, whereas the corresponding plot for the $\mathrm{Cu}$ doped case shows a smaller ( $8 \mathrm{~J} / \mathrm{kg} \mathrm{K}$ maximal value) but broader $-\Delta S_{m}$ peak centered near $300 \mathrm{~K}$. For near room temperature refrigeration, a $-\Delta S_{m}$ peak closer to $300 \mathrm{~K}$ is desirable. A commonly employed measure of the usefulness of a refrigerant is its refrigeration capacity $(\mathrm{RC})$, defined usually as the area under the $-\Delta S_{m}$ vs $T$ plot. Table I lists these values for the undoped and doped compounds with different metal additives ( $\mathrm{Al}, \mathrm{Co}, \mathrm{Cu}, \mathrm{Ga}$, or $\mathrm{Mn}$ ).

The RC values presented in this table are the integrals of

TABLE I. Refrigeneration capacities for the samples investigated in the present study.

\begin{tabular}{ccc}
\hline \hline Compound & $\begin{array}{c}\text { Refrigeration } \\
\text { capacity for }\end{array}$ & $\begin{array}{c}\text { Net } \\
\text { refrigeration } \\
\text { capacity }\end{array}$ \\
\hline $\mathrm{Gd}_{5} \mathrm{Ge}_{1.9} \mathrm{Si}_{2} \mathrm{Cu}_{0.1}$ & $359 \mathrm{~J} / \mathrm{kg}$ & $359 \mathrm{~J} / \mathrm{kg}$ \\
$\mathrm{Gd}_{5} \mathrm{Ge}_{1.9} \mathrm{Si}_{2} \mathrm{Ga}_{0.1}$ & $305 \mathrm{~J} / \mathrm{kg}$ & $305 \mathrm{~J} / \mathrm{kg}$ \\
$\mathrm{Gd}_{5} \mathrm{Ge}_{1.9} \mathrm{Si}_{2} \mathrm{Mn}_{0.1}$ & $320 \mathrm{~J} / \mathrm{kg}$ & $320 \mathrm{~J} / \mathrm{kg}$ \\
$\mathrm{Gd}_{5} \mathrm{Ge}_{1.9} \mathrm{Si}_{2} \mathrm{Co}_{0.1}$ & $368 \mathrm{~J} / \mathrm{kg}$ & $353 \mathrm{~J} / \mathrm{kg}$ \\
$\mathrm{Gd}_{5} \mathrm{Ge}_{1.9} \mathrm{Si}_{2} \mathrm{Al}_{0.1}$ & $355 \mathrm{~J} / \mathrm{kg}$ & $355 \mathrm{~J} / \mathrm{kg}$ \\
$\mathrm{Gd}_{5} \mathrm{Ge}_{2} \mathrm{Si}_{2}(\mathrm{Ames})$ & $305 \mathrm{~J} / \mathrm{kg}$ & $240 \mathrm{~J} / \mathrm{kg}$ \\
\hline \hline
\end{tabular}

$T \Delta S_{m}$ computed using the computational methods outlined in Ref. 8 and using the temperatures of half maximum as the limits of integration. A more proper measure is the net refrigeration capacity (NRC), also listed in Table I, wherein the average hysteresis loss for that material in the temperature range of its $-\Delta S_{m}$ vs $T$ peak has been subtracted from its RC value. The NRC value is a better indicator of a material's usefulness than either the RC or peak $-\Delta S_{m}$ value since it takes into account the losses due to cycling the magnetic field. The values reported in Table I clearly show that the NRC value for the undoped compound is about $50 \%$ smaller than those of the doped compounds, as also reported earlier for a Fe-doped alloy. ${ }^{5}$ The RC and NRC values for the cases of Bi- or Sn-doped compounds are not included in Table I, but they are very close to the values for the undoped $\mathrm{Gd}_{5} \mathrm{Ge}_{2} \mathrm{Si}_{2}$ compound. This is because these two metal additives had little or no effect on the presence of the fieldinduced transition or on the sizes of the hysteresis losses of the $\mathrm{Gd}_{5} \mathrm{Ge}_{2} \mathrm{Si}_{2}$ compound. They were also single phase materials.

\section{CONCLUSION}

Doping the $\mathrm{Gd}_{5} \mathrm{Ge}_{2} \mathrm{Si}_{2}$ compound with approximately $1 \%$ atomic fraction of $\mathrm{Cu}, \mathrm{Co}, \mathrm{Ga}, \mathrm{Mn}$, or $\mathrm{Al}$ resulted in results similar to those found earlier ${ }^{6}$ for the compound doped with the same amount of Fe. For these materials, both the field-induced transformation and the hysteresis observed on cycling the field between 0 and $3.98 \mathrm{MA} / \mathrm{m}(50 \mathrm{kOe})$ near $270 \mathrm{~K}$ were eliminated. Also, in all these alloys, the single phase structure of the $\mathrm{Gd}_{5} \mathrm{Ge}_{2} \mathrm{Si}_{2}$ compound was replaced by a structure comprised of one $\mathrm{Si}$-deficient majority phase with small amounts of Si-containing secondary phases located at the grain boundaries. One of the main effects of these dopants, therefore, was to dilute the $\mathrm{Gd}_{5} \mathrm{Ge}_{2} \mathrm{Si}_{2}$ compound (majority phase) of sufficient $\mathrm{Si}$ that it was no longer able to form the monoclinic phase. Low $T$ x-ray data support this conclusion. By contrast, the two dopants, $\mathrm{Bi}$ and $\mathrm{Sn}$, which did not form a multiphase structure upon their addition to the $\mathrm{Gd}_{5} \mathrm{Ge}_{2} \mathrm{Si}_{2}$ compound, did not eliminate the field-induced transformation or the magnetic hysteresis near $270 \mathrm{~K}$.

\section{ACKNOWLEDGMENTS}

The authors would like to acknowledge helpful discussions with R. D. McMichael and L. H. Bennett.

${ }^{1}$ V. K. Pecharsky and K. A. Gschneidner, Jr., Phys. Rev. Lett. 78, 4494 (1997).

${ }^{2}$ A. O. Percharsky, K. A. Gschneidner, Jr., and V. K. Pecharsky, J. Appl. Phys. 93, 4722 (2003).

${ }^{3}$ E. M. Levin, V. K. Pecharsky, and K. A. Gschneidner, Jr., Phys. Rev. B 62, R14625 (2000).

${ }^{4}$ A. Giguere et al., Phys. Rev. Lett. 83, 2262 (1999).

${ }^{5}$ V. Provenzano, A. J. Shapiro, and R. D. Shull, Nature (London) 429, 853 (2004).

${ }^{6}$ The use of manufacturers' names in this paper is only for specifying the experimental conditions and does not imply an endorsement by the authors or NIST.

${ }^{7}$ W. Choe et al., Phys. Rev. Lett. 84, 4617 (2000).

${ }^{8}$ K. A. Gschneidner, Jr., V. K. Pecharsky, A. O. Pecharsky, and C. B. Zimm, Mater. Sci. Forum 315, 69 (1999). 